\begin{tabular}{|c|c|c|}
\hline \multirow{2}{*}{$\begin{array}{r}\text { Case Reports in } \\
\text { Gastroenterology }\end{array}$} & \multicolumn{2}{|c|}{ Case Rep Gastroenterol 2019;13:225-229 } \\
\hline & $\begin{array}{l}\text { DOI: } 10.1159 / 000494554 \\
\text { Published online: April 23, } 2019\end{array}$ & $\begin{array}{l}\text { (c) } 2019 \text { The Author(s) } \\
\text { Published by S. Karger AG, Basel } \\
\text { www.karger.com/crg }\end{array}$ \\
\hline & $\begin{array}{l}\text { This article is licensed under } t \\
\text { International License (CC BY-NC } \\
\text { Usage and distribution for comm }\end{array}$ & $\begin{array}{l}\text { nons Attribution-NonCommercial } 4.0 \\
\text { ger.com/Services/OpenAccessLicense). } \\
\text { guires written permission. }\end{array}$ \\
\hline
\end{tabular}

\title{
Chronic Diarrhea Secondary to Newly Diagnosed VIPoma
}

\author{
Domenico A. Farina $^{a} \quad$ Katrina M. Krogh ${ }^{b} \quad$ Justin R. Boike \\ aDepartment of Medicine, Northwestern University, Chicago, IL, USA; ${ }^{b}$ Department of \\ Pathology, Northwestern University, Chicago, IL, USA; 'Division of Gastroenterology and \\ Hepatology, Northwestern University, Chicago, IL, USA
}

\section{Keywords}

VIPoma $\cdot$ Diarrhea $\cdot$ Pancreatic neuroendocrine tumor

\begin{abstract}
Vasoactive intestinal polypeptide-secreting tumors (VIPoma) are a rare pancreatic neuroendocrine tumor that can cause chronic diarrhea with 1 case per 10 million people per year. Diagnosis is made based on a combination of laboratory evaluation (serum VIP level), imaging findings (functional positron emission tomography-computed tomography [PET-CT]), and histological analysis (chromogranin A stain). We present a case of a male with 6 months of diarrhea and malaise who was found to have significant kidney injury and hypokalemia requiring admission to the medical intensive care unit. Subsequent laboratory evaluation while admitted eventually showed a low stool osmotic gap $(-11 \mathrm{mOsm} / \mathrm{kg})$ consistent with secretory diarrhea, in addition to significantly elevated VIP levels at $940 \mathrm{pg} / \mathrm{mL}$ (normal $<75$ ). Cross-sectional imaging with functional Gallium-68 dotatate PET-CT confirmed metastatic functional neuroendocrine tumor indicative of a VIPoma. Pathology on subsequent metastatic liver lesion aspiration was consistent with a well-differentiated VIPoma, and symptoms dramatically improved following initiation of octreotide therapy.




\section{Introduction}

Chronic diarrhea is common in the United States, with an estimated prevalence of 5\%, and is defined as $>200 \mathrm{~g}$ of stool per day for more than 4 weeks [1]. Diarrhea of $>1,000 \mathrm{~g}$ per day is pathologic and should be delineated by stool osmolality (Osm) to differentiate secretory from osmotic etiologies with further attention paid to investigating neuroendocrine etiologies [1]. Secretory diarrhea secondary to vasoactive intestinal polypeptide-secreting pancreatic neuroendocrine tumors (VIPomas) are rare, with an annual incidence of 0.2-0.5 cases per 1 million people per year [2]. This syndrome, first described by Verner and Morrison [3] in 1958 , is associated with $>2 \mathrm{~L}$ of watery stool per day, hypokalemia, and achlorhydria (WDHA syndrome).

\section{Case Presentation}

A 74-year-old male presented with several months of frequent, large-volume diarrhea with progressive weight loss. The patient endorsed having 10 to 12 watery stools per day and had experienced in excess of $30 \mathrm{lbs}$ of weight loss (16\% decrease from baseline weight). Past medical history was significant for hypertension, renal cell carcinoma requiring nephrectomy, thyroid hyperplasia with partial thyroidectomy and, most importantly, a pancreatic neuroendocrine tumor treated with distal pancreatectomy 9 years prior to presentation. His initial laboratory results were notable for a low potassium of $1.9 \mathrm{mmol} / \mathrm{L}$ (normal <3.5) and a serum Osm of $319 \mathrm{mOsm} / \mathrm{kg}$ (normal 275-295). Prior to hospital presentation, his diagnostic evaluation included a colonoscopy without evaluation of the terminal ileum though random colonic biopsies were unremarkable. He was then empirically trialed on a course of rifaximin for possible small intestine bacterial overgrowth followed by a course of cholestyramine for malabsorption diarrhea without any improvement in his symptoms.

The patient was admitted to the medical intensive care unit given significant elevation to $5.8 \mathrm{mg} / \mathrm{dL}$ in his creatinine (patient's baseline $1.1 \mathrm{mg} / \mathrm{dL}$ ) and electrocardiogram changes (presence of "u" waves) consistent with hypokalemia. He was volume resuscitated with normal saline and monitored on continuous telemetry while serum potassium was corrected with intravenous potassium chloride prior to transferring to a general medicine service. While admitted, stool Osm was measured as $330 \mathrm{mOsm} / \mathrm{kg}$. His calculated osmotic gap of -11 $\mathrm{mOsm} / \mathrm{kg}$ was suggestive of secretory diarrhea. Neuroendocrine markers were then sent, and the results were notable for a normal gastrin level, a somatostatin level of $65 \mathrm{pg} / \mathrm{mL}$ (normal $<31$ ), and a vasoactive intestinal polypeptide level of $940 \mathrm{pg} / \mathrm{mL}$ (normal <75).

The patient subsequently underwent endoscopic ultrasound of the pancreas with no masses appreciated in the head or duct of the pancreas. A 10-mm lymph node was found in the porta hepatis on endoscopic ultrasound, and fine-needle aspiration showed no malignant cells. Finally, positron emission tomography-computed tomography (PET-CT) Gallium-68 dotatate was performed and showed a single region of the pancreas as well as multiple liver lesions with abnormal activity. These imaging findings, in the setting of watery diarrhea, hypokalemia, and an elevated VIP level, supported a diagnosis of VIPoma. Symptomatic treatment was favored, and the patient was started on octreotide with rapid resolution of his chronic diarrhea within $24 \mathrm{~h}$.

The patient followed up with medical oncology and underwent aspiration of a liver lesion found on the prior PET-CT to help guide therapy. Pathology of the liver aspiration showed a 
proliferation index (Ki-67) of $2 \%$, which is consistent with a well-differentiated neuroendocrine tumor (Fig. 1). Given the pathology findings, oncology made the decision to continue with octreotide monotherapy.

\section{Discussion}

VIPomas are exceedingly rare with a reported incidence of 1 in 10 million [2, 4]. Most cases are diagnosed in children aged 2-4 years and adults aged $30-50$ years [5]. The vast majority of cases arise in the pancreas, and these tumors are much less common than pancreatic neuroendocrine tumors (PNET) that secrete insulin, glucagon, or gastrin, representing just $5.7 \%$ of all functional PNETs $[5,6]$. A minority of cases (5\% of all VIPomas) are associated with multiple endocrine neoplasia type 1 (MEN1 syndrome), which is characterized by tumors in the parathyroid gland, pancreatic islet cells, and pituitary gland [4]. Interestingly, 75\% of the VIPomas occur in the pancreatic tail, which is where our patient had previously undergone a distal pancreatectomy for PNET [2, 5]. A further $20 \%$ of the cases occur in neurogenic tumors (pheochromocytomas, ganglioneuromas) found in the retroperitoneum or adrenal glands [2]. Moreover, as was seen in our patient, $60-80 \%$ of the patients have metastatic disease at the time of diagnosis.

VIPoma-induced WDHA syndrome is characterized by profuse diarrhea often exceeding $1,000 \mathrm{~g}$ of stool per day that persists even after $72 \mathrm{~h}$ of fasting [2, 7]. This occurs as a result of VIP binding to intestinal epithelial cells, thereby upregulating cAMP and leading to secretion of electrolytes into the bowel lumen, causing profuse watery diarrhea [2]. Most patients experience diarrhea (89\%), weight loss (72\%), and hypokalemia (67\%) [7].

Diagnosis is made through laboratory evaluation and imaging studies. A serum VIP level $>75 \mathrm{pg} / \mathrm{mL}$ is consistent with a VIPoma [8]. Stool Osm should be consistent with a secretory diarrhea, which is defined as a stool osmotic gap of $<50$ [1]. In our patient, laboratory results showed a stool osmotic gap of $-11 \mathrm{mOsm} / \mathrm{kg}$ and a serum VIP level of $940 \mathrm{pg} / \mathrm{mL}$, consistent with VIPoma. Interestingly, $66 \%$ of the patients diagnosed with VIPomas also have elevations in other measurable serum islet cell peptides, such as gastrin and insulin [7]. Imaging is crucial for tumor localization and staging. Newer functional imaging with PET-CT Gallium-68 dotatate is $97 \%$ sensitive for the detection of VIPomas, as compared to the lower reported sensitivities of contrast-enhanced CT and magnetic resonance imaging at 80 and $85 \%$, respectively, which were traditionally used in the past [6,9].

By inhibiting VIP secretion, symptomatic management of diarrhea can be achieved with somatostatin analogues, such as octreotide, which ultimately led to resolution of our patient's symptoms [10]. In addition, somatostatin analogues have also shown tumor stabilizing effects in $50-60 \%$ of the PNETs [11]. In cases refractory to somatostatin analogues, glucocorticoids can be used to decrease symptoms of excess VIP [10]. Based on published guidelines, treatment should be guided by cellular mitotic rate and cellular proliferation (Ki-67) to determine grading, which our patient underwent following discharge [12]. Our patient had a lower Ki-67 corresponding to a grade 1, well-differentiated PNET (defined as Ki-67 <3\%) [12]. Given the prevalence of metastatic disease, curative resection of the pancreatic tail is only available to a minority of patients $[9,10]$. Due to the frequency of hepatic metastases, as was seen in our patient, therapy can be augmented with hepatic lobe resections and hepatic artery embolization or targeted ablation therapy [10]. Recently, both everolimus and sunitinib have been used for progressive nonresectable PNETs such as VIPomas with improvement in progression-free survival $[12,13]$. 
Overall, VIPomas are rare functional neuroendocrine tumors most commonly found in the pancreas and usually diagnosed after metastasis. Diagnosis is confirmed with an elevated serum VIP level and functional PET-CT. Treatment is aimed at symptom management for metastatic disease and surgery for isolated tumors, if possible.

\section{Statement of Ethics}

The authors have no ethical conflicts to disclose. Consent was obtained from the patient on May 23, 2018, and documented in Northwestern Memorial Hospital's Epic Systems 2015 Electronic Medical Record.

\section{Disclosure Statement}

The authors have no conflicts of interest to declare.

\section{Funding Sources}

The authors did not receive any funding.

\section{Author Contributions}

Domenico A. Farina: Drafted, prepared, revised, and edited the manuscript.

Katrina M. Krogh: Reviewed and prepared the pathology slides for the case and figures and edited the manuscript.

Justin R. Boike: Obtained patient consent, prepared, and edited the manuscript.

\section{References}

1 Fine KD, Schiller LR. AGA technical review on the evaluation and management of chronic diarrhea. Gastroenterology. 1999 Jun;116(6):1464-86.

2 Capella C, La Rosa S. VIPoma. In: La Rosa S, Sessa F, editors. Pancreatic Neuroendocrine Neoplasms. New York, NY. Cham: Springer; 2015. pp. 97-104.

3 Verner JV, Morrison AB. Islet cell tumor and a syndrome of refractory watery diarrhea and hypokalemia. Am J Med. 1958 Sep;25(3):374-80.

4 Fujiya A, Kato M, Shibata T, Sobajima H. VIPoma with multiple endocrine neoplasia type 1 identified as an atypical gene mutation. BMJ Case Rep. 2015 Nov;2015:bcr2015213016.

5 Ghaferi AA, Chojnacki KA, Long WD, Cameron JL, Yeo CJ. Pancreatic VIPomas: subject review and one institutional experience. J Gastrointest Surg. 2008 Feb;12(2):382-93.

6 Lam S, Liew H, Khor HT, Dalan R, Kon YC, Jong M, et al. VIPoma in a 37-year-old man. Lancet. 2013 Aug;382(9894):832.

7 Smith SL, Branton SA, Avino AJ, Martin JK, Klingler PJ, Thompson GB, et al. Vasoactive intestinal polypeptide secreting islet cell tumors: a 15-year experience and review of the literature. Surgery. 1998 Dec;124(6):1050-5.

8 Jensen RT, Cadiot G, Brandi ML, de Herder WW, Kaltsas G, Komminoth P, et al.; Barcelona Consensus Conference participants. ENETS Consensus Guidelines for the management of patients with digestive neuroendocrine neoplasms: functional pancreatic endocrine tumor syndromes. Neuroendocrinology. 2012;95(2):98-119. 
Farina et al.: Chronic Diarrhea Secondary to Newly Diagnosed VIPoma

9 Yao JC, Hassan M, Phan A, Dagohoy C, Leary C, Mares JE, et al. One hundred years after "carcinoid": epidemiology of and prognostic factors for neuroendocrine tumors in 35,825 cases in the United States. J Clin Oncol. 2008 Jun;26(18):3063-72.

10 Frilling A, Modlin IM, Kidd M, Russell C, Breitenstein S, Salem R, et al.; Working Group on Neuroendocrine Liver Metastases. Recommendations for management of patients with neuroendocrine liver metastases. Lancet Oncol. 2014 Jan;15(1):e8-21.

11 Rinke A, Müller HH, Schade-Brittinger C, Klose KJ, Barth P, Wied M, et al.; PROMID Study Group. Placebocontrolled, double-blind, prospective, randomized study on the effect of octreotide LAR in the control of tumor growth in patients with metastatic neuroendocrine midgut tumors: a report from the PROMID Study Group. J Clin Oncol. 2009 Oct;27(28):4656-63.

12 Kunz PL, Reidy-Lagunes D, Anthony LB, Bertino EM, Brendtro K, Chan JA, et al.; North American Neuroendocrine Tumor Society. Consensus guidelines for the management and treatment of neuroendocrine tumors. Pancreas. 2013 May;42(4):557-77.

13 Godard-Sebillotte C, Dramé M, Fagour C, Basileu T, Godaert L. When Symptomatic Treatment Becomes Antitumor Treatment for Vipoma: Opportunity for Frail Elderly Adults. J Am Geriatr Soc. 2016 Feb;64(2):449-50.
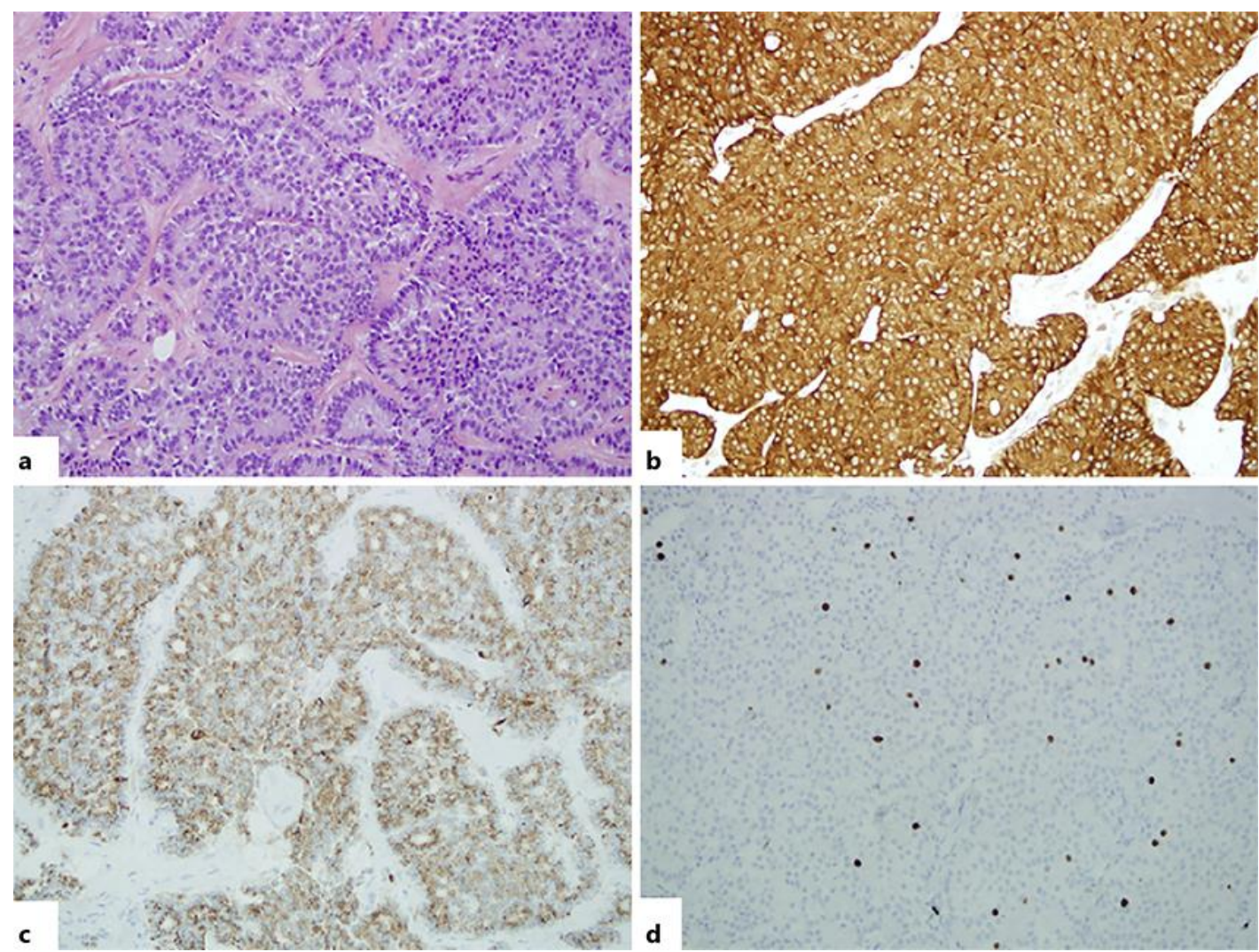

Fig. 1. a Core of liver mass in a patient with multiple liver lesions, pancreas mass, and diarrhea. Histology shows trabecular architecture of uniform cells with pale-pink cytoplasm and round, eccentrically located nuclei, consistent with well-differentiated PNET. H\&E. $\times 200$. b Synaptophysin, diffusely and strongly positive in tumor cells $(\times 200)$. c Chromogranin, apical positivity with moderate intensity $(\times 200)$. d Ki-67 highlights proliferation index of $2 \%$. H\&E. $\times 200$. 